\title{
Assessment of Gender Policy in Selected Tertiary Agricultural Education Institutions in Africa
}

\author{
Drame Yaye Aissetou1, Oluwole Matthew Akinnagbe ${ }^{2}$, Ochola Alfred ${ }^{1}$, \\ Chakeredza Sebastian ${ }^{1}$, Hien Mipro ${ }^{3}$ \\ ${ }^{1}$ African Network of Agriculture, Agroforestry and Natural Resources Education, Nairobi, Kenya \\ ${ }^{2}$ Department of Agricultural Extension \& Communication Technology, Federal University of Technology, Akure, \\ Nigeria \\ ${ }^{3}$ Institute of Rural Development, Polytechnic University of Bobo-Diuolasso, Bobo-Diuolasso, Burkina Faso \\ Email: a.yaye@cgiar.org, wolexakins@yahoo.com, miphien@gmail.com
}

Received 21 August 2015; accepted 21 September 2015; published 24 September 2015

Copyright (C) 2015 by authors and Scientific Research Publishing Inc.

This work is licensed under the Creative Commons Attribution International License (CC BY). http://creativecommons.org/licenses/by/4.0/

(c) (i) Open Access

\section{Abstract}

The paper assesses the existing gender policy document in fourteen (14) selected agricultural faculties and colleges in tertiary institutions in Africa. This paper is an output of research report on Programme of Strengthening Africa's Strategic Agricultural Capacity for Impact on Development (SASACID) implemented by the African Network for Agriculture, Agroforestry and Natural Resources Education (ANAFE). Data for the study were collected from 207 respondents (8 deans of ANAFE SASACID pilot institutions, 36 academic staff/lecturers of SASACID pilot institutions and 163 students of SASACID pilot institutions) through the use of online survey. Data collected were analysed and presented using frequency, percentage and charts. Results of the survey revealed that $25.0 \%$ of the institutions studied indicated that they had a formal gender policy document in place in their institutions with regards to staff recruitment and students' admission, while about $\mathbf{2 5 . 0 \%}$ had an informal gender practices on staff recruitment and students' admission. Higher proportion $(60.0 \%)$ of the institution had neither a formal policy document nor informal practices as regards staff recruitment and students admission. Some of the constraints faced by the Institutions with a gender policy were insufficient female applicants in agricultural courses, societal norms and remote location of some of the faculties/colleges of agriculture. To encourage both males and females to study agriculture in higher institutions of learning and to create and sustain a fair and just academic environment where both have equal opportunities, there is a need to have a gender policy document and the need to create awareness. 


\section{Keywords}

\section{Gender Policy, Tertiary Agricultural Education, Institutions, Africa}

\section{Introduction}

Agriculture is vital to people and economy of Africa, and many of those involved in agriculture as a business are women. Their input to the business of agriculture is essential. The vast continent has $60 \%$ of the world's uncultivated arable land, and most of it is unfarmed. In other parts, the potential for irrigation-based agriculture remains underutilized [1]. Forests, trees on farms and agroforestry systems contribute to food security, nutrition and livelihoods in several ways, including as a direct source of food, fuel, employment and cash income. They are fundamental to the survival of forest-dwellers; especially smallholders farm families, and are important providers of ecosystem services, including maintaining or restoring soil fertility, protecting watersheds and water courses. Agroforestry could complement forestry sector efforts in sustainable forest management by providing a set of tree-based conservation and production practices for agricultural lands [2].

The growing demand for existing markets, land and water can go a long way towards success in sustainable agriculture, forestry and agroforestry, other factors, such as good inputs, infrastructure, access to financing, and supportive government policies are also important. The Most important, behind most of these factors are the people that make this sustainable agriculture a reality — which brings us to the crucial importance of education and training. Being successful in today's agriculture, especially agribusiness, sectors demand education and training not only imparts technical skills but also trains students (both male and female) to be good communicators, capable managers, or quick-thinking entrepreneurs.

In many Africa institutions of higher education, gender issues are regarded with fear and trepidation. Gender advocates are stigmatized and viewed as promoting westernized, un-African and donor-inspired agenda. These attitudes especially from men are often masked with ignorance about gender issues and influence of existing gender biases; stereotypes in the society are being internalized and acted out in higher education context [3]. Over the past decade, African higher education institutions, Universities in particular, have been very keen to mainstream gender into their core functions of teaching, learning, research and administration systems. The proportions of women who are able to secure academic positions are largely dependent on their enrolment and completion of higher education [4]. Older institutions and some of the recent ones in Africa did not adopt any policies on gender equity until recently. This might be because the Europeans who were instrumental to the establishment of the institutions at that time had not adopted any gender-equality policies in access, output, and outcome in their own countries [5] [6].

If gender is regarded as one of the tenets of development, then mainstreaming gender in universities and colleges becomes an important matter that requires urgent attention, as it goes beyond effecting social justice and equity. It is equally a potent means for an exponential increase of the much-needed capacity in national development. However, today gender has become one of the most important areas by which the quality and effectiveness of an academic institution is judged. A gender policy provides an institutional framework within which actions on gender can be taken at all levels. It provides a framework that enables partner institutions to undertake initiatives that are mutually beneficial and lead to the promotion of gender justice and equity. An effective gender policy is supported by detailed rules and regulations to guide the institution towards more effective equity and equality strategies [3].

In view of the above scenario, the question is: do tertiary agricultural education institutions in Africa have gender policy in their programme? The purpose of this study is to assess the existing gender policy in selected tertiary agricultural education institutions in Africa by using pilot institutions of African Network of Agriculture, Agroforestry and Natural Resources Education (ANAFE) as a case study. ANAFE is a network of 140 Universities and colleges in 35 African countries, focusing on mainstreaming integrated education and training programmes in Agriculture, Agroforestry, Forestry and Natural Resources within African colleges and universities.

\section{Research Method}

The study was conducted in June, 2013 using the African Network of Agriculture, Agroforestry and Natural Resources Education (ANAFE) pilot institution. ANAFE is a network of 140 universities and technical colleges in Africa and is launched in 1993 to address policy and institutional barriers in the establishment of agroforestry 
education. In 2003, ANAFE's mandate was expanded to encompass reforming education and training programmes in Agriculture, Forestry, Agroforestry, and natural resources to make them more responsive to development needs. ANAFE initiated and implemented a programme called "Strengthening Africa's Strategic Agricultural Capacity for Impact on Development" (SASACID). The programme was launched in the year 2011. Sixteen ANAFE institutions were used as Pilot Institutions (PIs) for the programme. This research was conducted in all the sixteen pilots institutions used by ANAFE. Out of these, fourteen ANAFE institutions that submitted their survey were used for the study. The fourteen (14) ANAFE pilot institutions in Africa that responded to this study include Botswana College of Agriculture (Botswana), ENSA-University of Thies and Gaston Berger University (Senegal), Kenyatta University (Kenya), Mulungushi University (Zambia), Nyabyeya Forestry College (Uganda), Polytechnic University of Bobo Dioulasso (Burkina Faso), University of Dschang (Cameroon), University of Ghana (Ghana), University of Nsukka (Nigeria), University of Kordofan (Sudan), University of Pretoria (South Africa) and Zimbabwe College of Forestry (Zimbabwe) as indicated in Table 1.

Three versions of the same survey instruments were developed and administered to the three target groups: the Pilot Institutions (PI survey), staff members (staff survey), and students (student survey). The survey instruments were validated by field administration to ensure that the instruments collect what it is meant to collect. These instruments were sent to these three groups of respondents (deans of faculty, lecturers and students) using email. The respondents prefer to be anonymous. The completed survey instruments were also returned by the respondents through email. The survey instruments for the PI focused on four areas: a brief institutional profile, a human resource profile, gender policy, and questions around enrollment, such as number of students in agriculture/agribusiness programmes. The staff survey collected biographical information as well as information about the courses staff members taught, followed by a set of questions that asked respondents to describe and evaluate the gender policy at the institution. The survey to the students collected basic biographical information on the students' motivation for their field of study, and sought to establish the students' awareness of the gender policy at their various institutions. A total of fourteen (14) institutions, representing $87.5 \%$ of the response rate, thirty-six (36) academic staff (lecturers) representing $56.3 \%$ of the response rate and one hundred and sixty three (163) students responded to the survey representing $84.0 \%$ of the response rate were used for the study. Data collected were analyzed and presented using descriptive statistics such as frequency, percentages and charts.

\section{Results and Discussion}

\subsection{Existence of Gender Policy or Practices on Staff Recruitment}

Data in Table 2 show that only two (2) institutions out of those surveyed, have a gender policy or practices in their institution as regards to staff recruitment. The institutions are: Nyabyeya Forestry College, Uganda which established its gender policy in the year 2009 and the University of Kordofan, Sudan which established its

Table 1. List of the institutions and respondents that participated in the survey.

\begin{tabular}{|c|c|c|c|c|}
\hline Institution & Country & Deans Survey & Staff Survey & $\begin{array}{c}\text { Students } \\
\text { Survey }\end{array}$ \\
\hline Botswana College of Agriculture & Botswana & $\mathrm{x}$ & $\mathrm{x}$ & $\mathrm{x}$ \\
\hline Gaston Berger University & Senegal & $\mathrm{x}$ & $\mathrm{x}$ & $\mathrm{x}$ \\
\hline Kenyatta University & Kenya & & $\mathrm{x}$ & $\mathrm{x}$ \\
\hline Mulungushi University & Zambia & $\mathrm{x}$ & $\mathrm{x}$ & $\mathrm{x}$ \\
\hline Nyabyeya Forestry College & Uganda & $\mathrm{x}$ & $\mathrm{x}$ & $\mathrm{x}$ \\
\hline Polytechnic University of Bobo-Diuolasso & Burkina Faso & $\mathrm{x}$ & $\mathrm{x}$ & $\mathrm{X}$ \\
\hline Université de Thiès & Senegal & $\mathrm{x}$ & & $\mathrm{x}$ \\
\hline University of Dschang & Cameroon & & $\mathrm{x}$ & $\mathrm{x}$ \\
\hline University of Ghana & Ghana & & $\mathrm{x}$ & $\mathrm{x}$ \\
\hline University of Nairobi & Kenya & & $\mathrm{x}$ & $\mathrm{x}$ \\
\hline University of Nigeria, Nsukka & Nigeria & & $\mathrm{x}$ & $\mathrm{x}$ \\
\hline University of Kordofan & Sudan & $\mathrm{x}$ & $\mathrm{x}$ & $\mathrm{x}$ \\
\hline University of Pretoria & South Africa & & & $\mathrm{x}$ \\
\hline Zimbabwe College of Forestry & Zimbabwe & $\mathrm{x}$ & $\mathrm{x}$ & $\mathrm{x}$ \\
\hline
\end{tabular}

$\mathrm{x}=$ Survey response submitted. 
Table 2. Existence of Gender policy with regard to staff recruitment.

\begin{tabular}{|c|c|c|c|}
\hline Institution & $\begin{array}{c}\text { Formal gender } \\
\text { policy }\end{array}$ & $\begin{array}{l}\text { Informal } \\
\text { Practices }\end{array}$ & $\begin{array}{l}\text { No Formal Policy } \\
\text { or Practices }\end{array}$ \\
\hline Botswana College of Agriculture, Botswana & & & $\mathrm{x}$ \\
\hline Gaston Berger University, Senegal & & & $\mathrm{x}$ \\
\hline Mulungushi University, Zambia & & $\mathrm{x}$ & \\
\hline Nyabyeya Forestry College, Uganda & $\mathrm{x}$ & & \\
\hline Polytechnic University of Bobo-Dioulasso, Bobo-Diuolasso & & & $\mathrm{x}$ \\
\hline Université de Thiès, Senegal & & $\mathrm{x}$ & \\
\hline University of Kordofan, Sudan & $\mathrm{x}$ & & \\
\hline Zimbabwe College of Forestry, Zimbabwe & & & $\mathrm{x}$ \\
\hline
\end{tabular}

gender policy in the year of 2001. According to the respondents, University of Kordofan, Sudan have the gender policy as regards staff recruitment because of the need to meet gender balance in the Faculty and avoid unfairness towards females so as to provide equal opportunities for increasing the proportion of female staff at the institution.

Further analysis shows that, through the policy, institutions hoped to recruit more female staff members and provide existing staff members with opportunities for a successful academic and scientific career. Specific practices used to recruit and retain more women include: a bias in recruiting exceptional female students immediately after graduation; providing scholarships for female staff members to study in the country and/or abroad; minimizing the teaching load in case of pregnancy and providing time off for maternity leave; and deliberately retaining some positions for women (i.e., setting up a quota system).

Mulungushi University, Zambia and Université de Thiès, Senegal indicated that though they have no formal gender policy as regards staff recruitment, informal practices do exist to promote gender balance. The remaining four institutions (Botswana College of Agriculture, Gaston Berger University, Senegal, Polytechnic University de Bobo Dioulasso, and the Zimbabwe College of Forestry) reported having neither a formal gender policy nor any practices in place on staff recruitment.

A formal workplace gender equality policy can assist an organization or institution to provide both women and men access to equal opportunities; including equal remuneration for work of equal or comparable value; remove barriers to the full and equal participation of women in the workforce [7]. Many organizations as noted by [8] have gender policies or strategies in place that aim to improve the status of women, some of which address the issue of recruitment. Most of these strategies outline specific targets for recruitment of women to achieve organizational goals with regard to gender balance. For example, United Nations Gender Balance Strategy for the United Nations Secretariat: A Strategic Action Plan, 2010-the strengthening of recruitment and selection is a main focus, and concrete actions are identified to achieve this goal. Also, UNDP Gender Equality Strategy, 2008-2011 and UNESCO Priority Action Plan for Gender Parity include recruitment as one of its basic axes, along with training and mentoring and work life balance.

Interventions in many African Higher Education Institutions were largely driven by International resources. Of important note is the Carnegie Corporation of New York and the UK Department for International Development (DFID). Key intervention in gender mainstreaming in Universities were hinged on Women's Access to Higher Education, Gender Equity in Staff Development and Curriculum Transformation. Gender initiatives include the establishment of a Women and Documentation Centre providing a forum for research, advocacy and documentation of women's issues in collaboration with other private and non-governmental organizations. University curricula experienced transformation through engendering and staff development support were provided to increase women's access to capacity development that can be reflected in quality of researches and publication by women, enhanced curriculum delivery and mentorship [4].

Academic support in the form scholarship opportunity was created for female students to improve their chance for completing their career in record time. Although gender courses have been introduced into various faculties and departments, these efforts have usually been ad hoc and based on the commitment of individual Lecturers, Deans, and Vice-chancellors. All these efforts have culminated into a concerted, well-synchronized policy and 
plan for integrating gender into the university as a whole. Only very few universities have in place plans and policies for equal opportunity in employment, or against sexual harassment, racial, ethnic and sexual discrimination. African universities, with a notable role of training the future minds of African leaders, must necessarily embrace gender equity principles as core values. To have a structured, and informed change, African Universities need to embrace a system wide gender policy which will guide actions, and plans to bring about gender equity and gender justice within and outside the university system [9].

\subsection{Existence of Gender Policy on Staff Recruitment}

Results in Table 3 obtained from the staff (academic staff) on the existence of gender policy in their respective institutions with regard to staff recruitment reveal that all (100\%) staff who responded to the survey from the University of Kordofan, Sudan, confirmed that the institution has a gender policy on staff recruitment. This is in conformity with the early findings from the University authority that there is a gender policy on staff recruitment. In Nyabyeya Forest College Uganda, only 20\% of the staff affirmed existence of a formal gender policy with regard to staff recruitment while $80 \%$ said what was in place were informal practices. The discrepancy in response between the principal contact person for the institution and the staff could be as a result of the communication gap.

For Polytechnic University of Bobo-Dioulasso Burkina Faso, Botswana College of Agriculture, and Zimbabwe College of Forestry, all (100\%) of the respondents confirmed lack of a formal policy on gender with regards to staff recruitment. This is also in agreement with the earlier findings from the University authority as indicated in Table 2. There is no formal gender policy in the institution. About $50 \%$ of the staff of the Gaston Berger University, Senegal reported that there is no formal gender policy in the institution while $33.3 \%$ and $16.7 \%$ of the academic staff asserted that there is a formal gender policy and informal practices on staff recruitment in their university. Half of the staff alluded to the earlier findings that there is no formal gender policy in the institutions. The other half with varied opinion could also be as a result of their perception that informal practices equate to existence of gender policy on gender recruitment.

Academic staff reported that while their institutions have no formal gender policy, informal practices do exist. Some of these practices are: encouraging women to apply for positions and funding opportunities; creating an environment where women are respected and protected as per traditions and beliefs; promoting women into leadership positions; setting a quota of at least 30\% women on staff; zero tolerance for gender-based harassment and discrimination among employees; and decent accommodation is made available for female lecturers. According to staff respondents, institutions with a formal gender policy for staff indicated that those policies were

\section{Table 3. Existence of gender policy on staff recruitment.}

\begin{tabular}{|c|c|c|c|}
\hline Institution & $\begin{array}{c}\text { Formal Gender } \\
\text { Policy (\%) }\end{array}$ & $\begin{array}{c}\text { Formal \& Informal } \\
\text { Practices } \\
(\%)\end{array}$ & $\begin{array}{c}\text { Formal Policy } \\
\text { or Practices } \\
(\%)\end{array}$ \\
\hline Botswana College of Agriculture & - & - & 100 \\
\hline Gaston Berger University, Senegal & 33.3 & 16.7 & 50.0 \\
\hline Kenyatta University, Kenya & 20.0 & 40.0 & 40.0 \\
\hline Mulungushi University, Zambia & - & 100.0 & - \\
\hline Nyabyeya Forestry College, Uganda & 20.0 & 80.0 & - \\
\hline Polytechnic University of Bobo-Dioulasso, Burkina Faso & - & - & 100.0 \\
\hline University of Dschang, Cameroon & - & 100.0 & - \\
\hline University of Ghana, Ghana & - & 100.0 & - \\
\hline University of Kordofan, Sudan & 100.0 & - & - \\
\hline University of Nairobi, Kenya & 66.6 & - & 33.4 \\
\hline University of Nigeria, Nsukka, Nigeria & - & - & 100 \\
\hline Zimbabwe College of Forestry, & - & - & 100 \\
\hline
\end{tabular}


put in place between 2008 and 2011. They also asserted that the overall objectives of the policy and practices were to create and sustain a fair and just academic environment where men and women have equal opportunities, voice, rights and access to resources, so that all categories of persons can realize their full potential and contribution within a community of scholars with a culture of mutual respect. Some also asserted that this is to implement government policies and international conventions and guidelines on gender, disability, and marginalization which have forced the University to formulate and implement strategies addressing gender policies.

A number of United Nations system organizations make reference to gender balance in their recruitment policies and procedures. UNIDO, for example, refers to the goal of 50/50 gender balance in its administrative instruction on succession planning. United Nations Relief and Works Agency mentions candidates of the underrepresented gender in its guidance for final selection. Frequently, however, no specific guidance is provided beyond the vague phrase of giving "due respect to gender balance" [8]. There are large gender disparities between women and men in higher education institutions. A study by the Institute of Education, London University, as part of its study entitled Gender Equity in Commonwealth Higher Education in 2005, shows that there is gender in enrolments only in South Africa, out of the four African countries in the study. The study outlines the challenges of social class, poverty, race and the quality of earlier education complicate the picture. There is a sizeable gender gap in the staffing situation at all levels. However it is particularly striking at the higher decision-making levels, where in four Commonwealth African universities, the percentage of women at professor, associate professor and senior lecturer level is decidedly lower than the percentage of men. At the lowest level of academic appointments, that of assistant lecturer, the percentage of women is surprisingly low, indicating that there is little focus on gender equity and gender equality in the staff development programme in these institutions [3].

\subsection{Gender Policy and Practices on Enrolment of Students}

Table 4 focused on gender policy and practices with regard to student enrollment. Three institutions have a gender policy with regard students' enrolment. The institutions are: Nyabyeya Forestry College Uganda, Polytechnic University of Bobo-Dioulasso Burkina Faso and University of Kordofan Sudan. It is of interest to know that the Polytechnic University of Bobo-Dioulasso does not have a gender policy for staff recruitment, but have a formal gender policy for students' enrolment. The reasons for this as pointed out by the management is to increase the number of female students in agricultural education programmes; increase the number of women working in senior positions in agriculture; and to mitigate poverty affecting women.

Botswana College of Agriculture and Zimbabwe College of Forestry had no formal policy or informal gender practices in place. Instead, these institutions reported that students are recruited by merit, their choice of programme and, where it applies, their ability to pay, without regard to gender issues. Mulungushi University Zambia and Université de Thiès Senegal reported that, though they had no formal policy, informal practices were in place. In contrast, Gaston Berger University reported having no formal policy but rather informal practices. These informal practices, to encourage students' enrolment include: granting additional scholarship funding for female agricultural students, provide social services for women at the university.

Table 4. Gender policy on enrolment of students.

\begin{tabular}{|c|c|c|c|}
\hline Institution & $\begin{array}{c}\text { Formal } \\
\text { Gender Policy }\end{array}$ & $\begin{array}{c}\text { Formal or } \\
\text { Informal } \\
\text { Practices }\end{array}$ & $\begin{array}{l}\text { No Formal } \\
\text { Policy or } \\
\text { Practices }\end{array}$ \\
\hline Botswana College of Agriculture, & & & $\mathrm{x}$ \\
\hline Gaston Berger University, Senegal & & $\mathrm{x}$ & \\
\hline Mulungushi University, Zambia & & $\mathrm{x}$ & \\
\hline Nyabyeya Forestry College, Uganda & $\mathrm{x}$ & & \\
\hline Polytechnic University of Bobo-Diuolasso, Burkina Faso & $\mathrm{x}$ & & \\
\hline Université de Thiès, Senegal & & $\mathrm{x}$ & \\
\hline University of Kordofan, Sudan & $\mathrm{x}$ & & \\
\hline Zimbabwe College of Forestry, & & & $\mathrm{x}$ \\
\hline
\end{tabular}


Studies have shown that there is no gender equity in university education in Africa, and there is a need to ensure adequate representation of women in higher education [10]. A desk study of a selection of African higher education institutions shows that there is a sizeable gender gap, related to particular areas and levels of study. At undergraduate level, more women cluster around certificate and diploma courses than degree courses. At graduate level, there may be fewer women at master's and doctoral level. Global inequity between the education of men and women has been internationally recognized as a human rights and development challenge for several years [11]. This recognition has been manifested through several international accords, including the Convention on the Elimination of All Forms of Discrimination Against Women (1979); Education for All (1990); the Beijing Platform for Action (1995); the Dakar Framework for Action (2000); the Commonwealth Plan for Action for Gender Equality (2005-2015); regional protocols such as the African Union's Gender Policy (2009); and sub-regional protocols such as the Southern African Development Community's (SADC) Protocol on Gender and Development (2008-2015). Most notably, the international community met at the Millennium Summit of the United Nations in 2000 to adopt the United Nations Millennium Declaration (Resolution 55/2) in September 2000 and subsequently the 8 Millennium Development Goals (MDGs).

\subsection{Proportion of Students of the Awareness of Gender Policy on Enrolment}

Data in Figure 1 show that more than half (55.0\%) of the students were not aware of the existence of a gender policy in their various Faculty or Department in the institutions. This is significantly higher than the 25\% reported by PIs. However, the difference may be due to the fact that gender policy exists in institutions where administrators did not respond to the survey request, while the students did.

Out of the $45.0 \%$ of the students that are aware of the gender policy, Figure 2 shows the proportion of students on institution basis that are aware of the gender policy. About $89 \%$ and $86 \%$ of the students of the Zimbabwe College of Forestry, Zimbabwe and Nyabyeya Forestry College Uganda were aware of the gender policy in their institution. This is in line with the previous finding that gender policy exists in those institutions. Although the Zimbabwe College of Forestry does not have a formal gender policy in place, students report they are aware of the informal practices with the overall aim to have an absence of discrimination of all types (age, sex, race, etc.) and that this creates a positive and inclusive atmosphere. Also $70.0 \%, 63.2 \%$ and $60.0 \%$ of students in Kenyatta University Kenya, University of Nairobi Kenya and Mulungushi University, Zambia were respectively aware of the gender policy in their institutions while $52.6 \%$ of students of Polytechnic University of Bobo-Dioulasso Burkina Faso were aware of gender policy in their institution. Awareness is very important in executing gender policy. The low awareness could also affect the implementation of the programme. This could be the communication channel used by the institution or inability of students reading the university laid down principles and law before gaining admission.

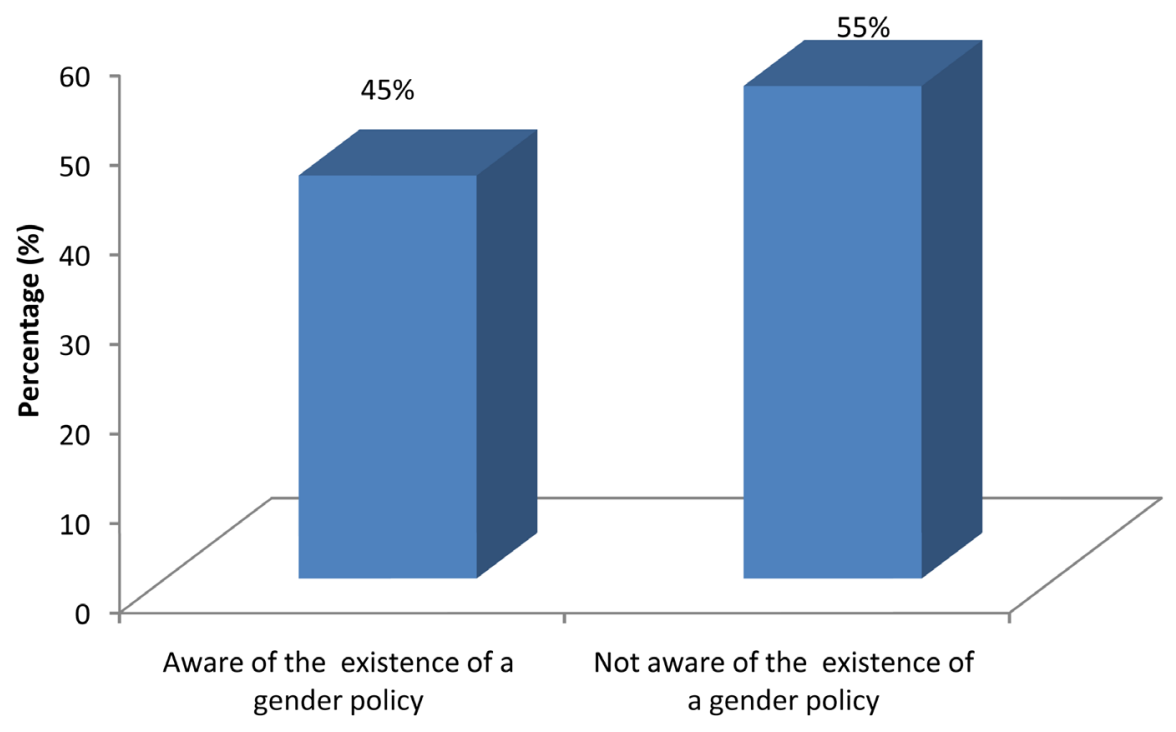

Figure 1. Students' awareness of gender policy in the institutions. 


\subsection{Constraints Faced in the Implementation of Informal Gender Policy}

The major constraints faced in the implementation of the formal policy and informal practices on staff recruitments in agricultural faculties in selected institutions as indicated by the staff in Figure 3 include: recruitment of staff is done at the faculty level (7.0\%), not enough female applicants (43.0\%), societal norms (36.0\%) and remote location of the institutions (7.0\%). Remote location of some agricultural colleges/faculties of the institution presents a barrier for females who may have family and other traditional responsibilities, which come with being women. Other constraints as indicated in others which constituted 10.0\% include: female lecturers fail to concentrate at the college/faculties when the family is away; difficult for both spouses to find jobs at same institution; remote location makes it difficult to obtain additional jobs and consultancies (generally used to supplement income); and requirement of a $\mathrm{PhD}$ for all renewable contract positions.

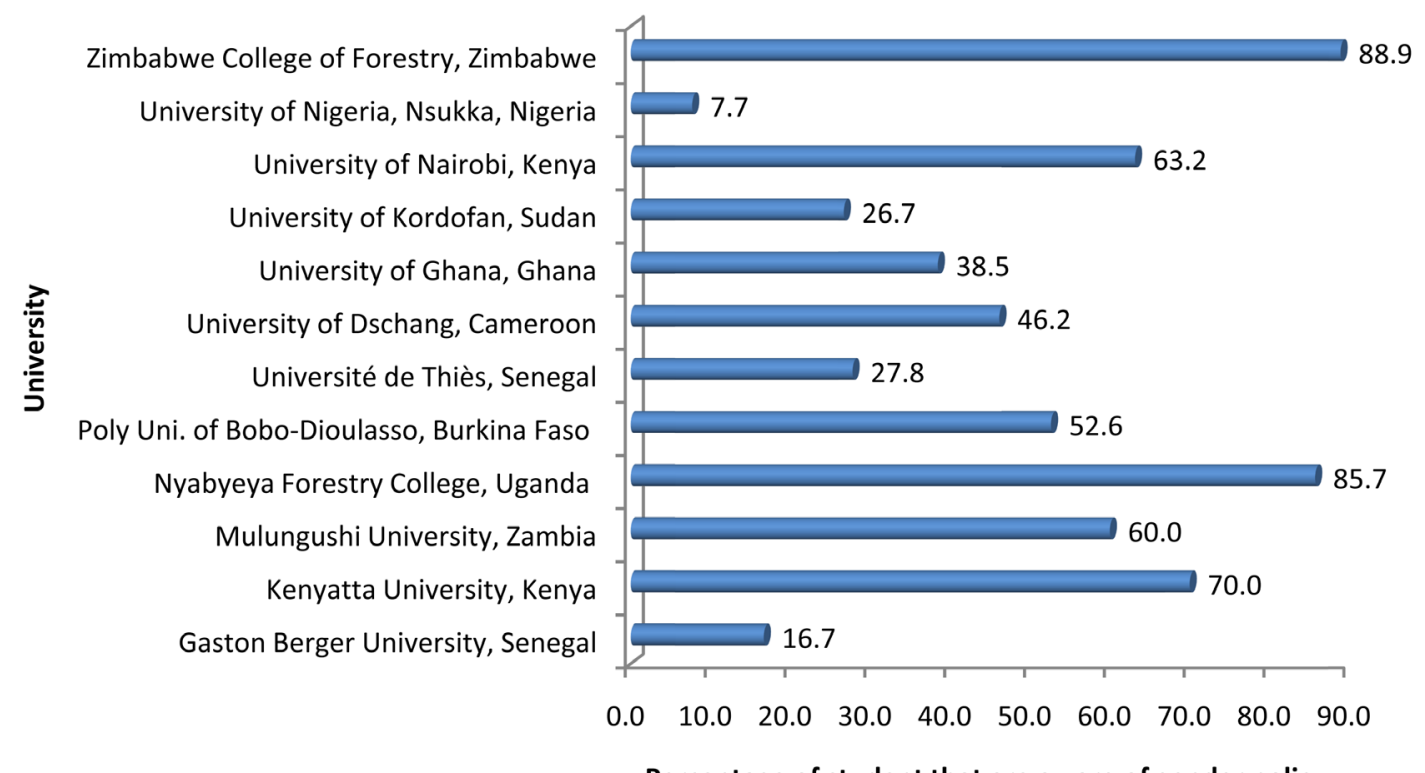

Figure 2. Proportion of students that are aware of gender policy in various institutions.

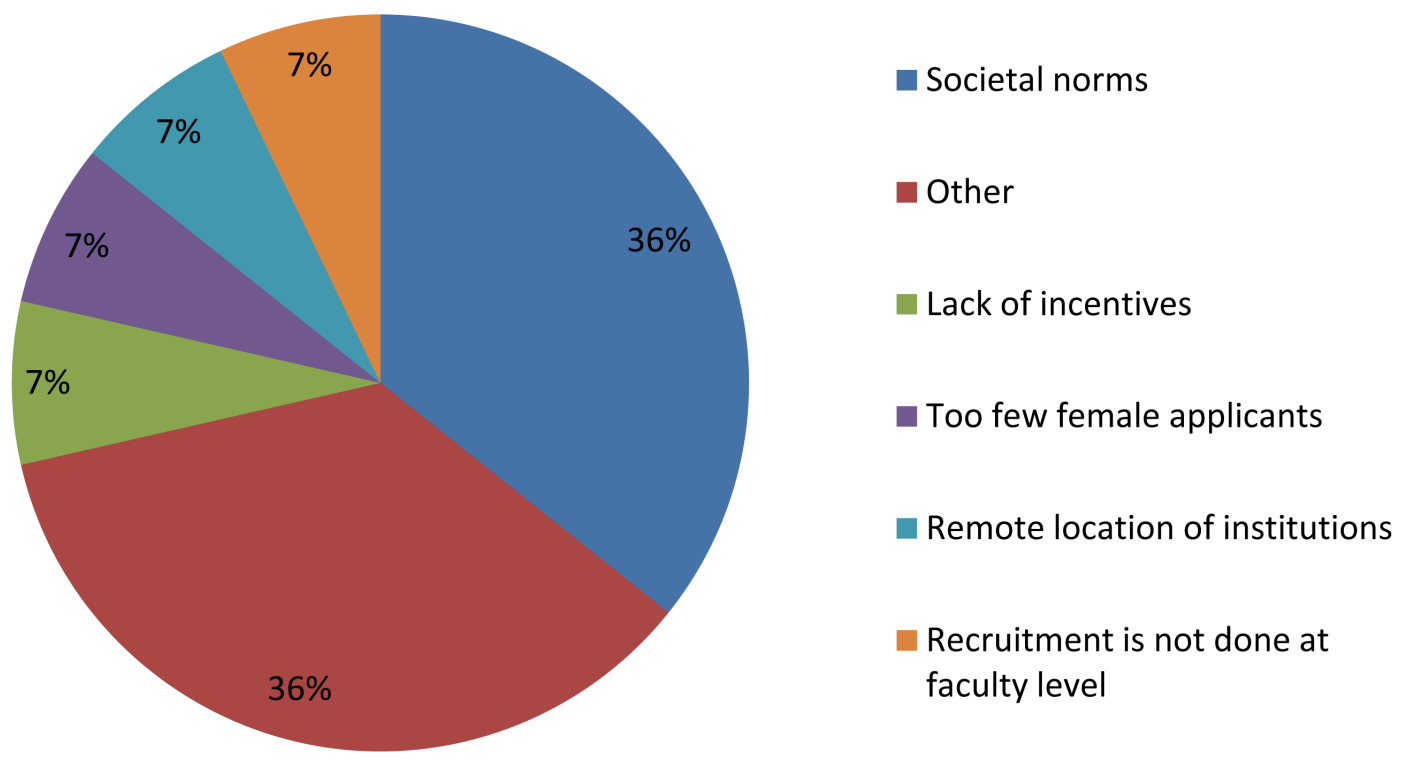

Figure 3. Constraints to implementation of gender policy and informal practices. 


\section{Conclusion and Recommendation}

Gender equality in education is an integral instrument for economic growth. In global and national discourses, education is framed as an engine of growth that fuels national economies and sustainable development. Investment in education for both boys and girls has been shown consistently to be one of the most important determinants of development, with positive implications for all other measures of progress. It is therefore critically important that policies targeting widening participation for female students also ensure that disadvantaged female students access such opportunities. At present, formal gender policy documents exist only in few institutions where they exist, they are introduced recently. Gender-equitable access to higher education must be an integral part of any strategy to promote long-term development in universities. Therefore, universities and colleges must be sensitized to the issue and take deliberate steps to redress the imbalance. This paper recommends that institutions should create and sustain a fair and just academic environment where men and women have equal opportunities, voice, rights and access to resources, so that all can realize their full potential and contribution within a community of scholars with a culture of mutual respect. This could be achieved when a gender policy is instituted.

\section{Acknowledgements}

The authors would like to appreciate the Swedish International Development Agency (Sida) for the financial support for this study.

\section{References}

[1] World Bank (2013) Growing Africa: Unlocking the Potential of Agribusiness.

[2] Ruark, G., Schoeneberger, M. and Nair, P.K. (2003) Roles for Agroforestry in Helping to Achieve Sustainable Forest Management.

http://maxa.maf.govt.nz/mafnet/unff-planted-forestry-meeting/conference-papers/roles-for-agroforestry.htm\#2

[3] Association of African Universities (AAU) (2006Toolkit for Mainstreaming Gender in Higher Education in Africa. Association of African Universities, Accra, 149.

[4] Taiwo, M.O. (2014) Best Practices in Gender Mainstreaming in the Academia: Lessons from African Higher Education Institutions. International Journal of Humanities Social Sciences and Education, 1, 81-87

[5] Assié-Lumumba, N.T. (2007) Human Capital, Human Capabilities, and Gender Equality: Harnessing the Development of Human Potential as a Human Right and the Foundation for Social Progress. In: Taiwo, M.O (2014) Best Practices in Gender Mainstreaming in the Academia: Lessons from African Higher Education Institutions. International Journal of Humanities Social Sciences and Education, 1, 81-87.

[6] Oanda, I. and Akudolu, L. (2010) Addressing Gender Inequality in Higher Education through Targeted Institutional Reponses: Field Evidence from Kenya and Nigeria. In: O’Hara, S., Ed., Higher Education in Africa: Equity, Access Opportunity, Institute Of International Education (IIE), New York, 23.

[7] Workplace Gender Equality Agency (2015) Developing a Workplace Gender Equality Policy. www.wgea.gov.au

[8] United Nations (2012) Staff Recruitment in United Nations System Organizations: A Comparative Analysis and Benchmarking Framework: Gender Balance and Geographical Distribution. Prepared by Papa Louis Fall and Yishan Zhang, Geneva, 24.

[9] Aina, O.I. (2013) Gender Equity and Higher Education in Africa. Lead Paper Presented at the 1st International Interdisciplinary Conference on Gender and Higher Education in Africa: Emerging Issues, 25.

[10] Assie-Lumumba, N. (2006) Empowerment of Women in Higher Education in Africa: The Role and Mission of Research. UNESCO Forum Occasional Paper Series Paper No. 11, University of Cape Town, Cape Town.

[11] Ramsey, R. (2013) Building Foundations of Inclusion \& Progress: Understanding Gender Equity for Higher Education Stakeholder Relations in Africa. Policy Brief No 2. 